\title{
El "impacto" de las políticas nacionales de ciencia y técnica sobre las publicaciones científicas
}

\author{
The "impact" of national science and technology policies \\ on scientific publications
}

En el marco del $V$ Congresso Brasileiro de Ciências Sociais e Humanas em Saúde realizado en San Pablo entre el 17 y el 20 de abril de 2011, se llevó a cabo el Fórum de Editores de Revistas da Área de Ciências Sociais y Humanas en Saúde, en el que se analizaron y discutieron los parámetros de clasificación de las revistas científicas para el área salud colectiva, adoptados por la Coordenação de Aperfeiçoamento de Pessoal de Nível Superior (CAPES), dependiente del Ministerio de Educación de Brasil. Los editores allí presentes elaboraron un documento, que reproducimos al final de este texto, en el que destacan "la urgente necesidad de revisión de los parámetros de clasificación de las revistas en el área de salud colectiva de la CAPES".

Cabe traer a la memoria otro documento, redactado durante el Encuentro Iberoamericano de Editores Científicos, EIDEC 2010, y publicado en Salud Colectiva (1), en el que los editores de revistas científicas argentinas de diversas áreas solicitaban la revisión de los criterios de clasificación utilizados por el Consejo Nacional de Investigaciones Científicas y Técnicas (CONICET).

Ambos escritos plantean una problemática similar: los organismos nacionales de evaluación de la producción científica priorizan las publicaciones editadas por la gran industria editorial científica, por sobre los productos editoriales de circulación internacional editados en sus propios países.

En el caso brasileño, los parámetros de clasificación de las publicaciones científicas son generados para cada una de las 47 áreas actualmente definidas en el sistema Qualis (2), cuyos criterios están plasmados en documentos de acceso público (3). A partir de estos parámetros, las publicaciones científicas se clasifican en: A1 (el más elevado); A2; B1; B2; B3; B4; B5; C (con peso cero). Según los nuevos criterios, establecidos en 2009, para que una revista sea considerada A1 dentro del área salud colectiva (4), por ejemplo, debe estar indizada en la base Scopus, con un índice $\mathrm{H}$ por encima del percentil 95, o incluida en el Journal Citation Report (JCR) con un factor de impacto por encima de 4,0. Si bien resulta cuestionable medir la calidad científica de una publicación a través de un indicador de citación (5), la cuestión no parece centrarse allí, sino en la decisión del propio Estado brasileño de desterrar a las revistas brasileñas de las categorías más altas, subiendo el valor del factor de impacto requerido a medida que las publicaciones brasileñas se acercan a los estratos superiores:

El criterio anterior indicaba, como punto de corte, un factor de impacto igual a 1. Recientemente, algunas revistas brasileñas consiguieron, con enormes esfuerzos, alcanzar ese nivel. Sin embargo, los nuevos criterios [...] establecieron puntos de corte mucho más elevados. De adoptarse esta medida, las revistas brasileñas pasarían a ser relegadas por los orientadores y alumnos de posgrado -los grandes productores de la ciencia brasileña- creándose así un círculo vicioso en el que sería difícil la supervivencia de nuestras revistas. (6) [Traducción nuestra]

En el caso argentino no hay un documento público que establezca criterios claros de clasificación de las revistas científicas. Los organismos nacionales evalúan y ponderan la producción de los investigadores según en qué revistas 
hayan publicado, pero: ¿qué criterios se utilizan para esa evaluación?

En los manuales de procedimiento de los integrantes de las comisiones asesoras encargadas de elaborar los dictámenes dentro del Sistema Integral de Gestión y Evaluación (SIGEVA) del CONICET, se explicita el procedimiento pero no el criterio para la evaluación de las publicaciones en revistas científicas del postulante:

Grupo: Permite clasificar a las publicaciones en revistas en tres grupos o lotes de calidad (se visualizan en un menú desplegable con las opciones 1,2 y 3 ).

Nota: Cada Comisión Asesora establecerá el criterio para la asignación en cada grupo, antes de realizar la evaluación individual. Esta opción no aparece para los otros tipos de producción científica. (7) [Cursivas del original]

El texto del manual deja en claro que la clasificación existe, es decir, que se ponderan las revistas en tres niveles diferenciados, pero se desconocen los criterios para establecer esa ponderación dado que son establecidos por cada Comisión Asesora.
Los criterios de clasificación CapesQualis de Brasil proponen categorías inalcanzables para las propias revistas brasileñas, que los editores brasileños vienen rechazando y cuestionando orgánicamente a través de la propia Associação Brasileira de Editores Científicos (8), en editoriales $(6,9-11)$ y documentos de asociaciones $(12,13)$. En el caso argentino estos criterios están vedados, tanto para los autores como para los editores, lo que impide saber si se hace un uso indiscriminado de los indicadores como el factor de impacto del JCR. Ambas situaciones presentan un matiz similar, pero una gran diferencia en cuanto a la organización y respuesta por parte de los editores de ambos países.

Para cerrar, y dejarlos con la lectura del documento, vale la pena citar el fragmento final de la carta abierta del editor responsable de la revista médica Clinic, dirigida a Jorge Guimarães, Presidente de CAPES:

Faça o que é preciso, Jorge: mande o novo Qualis para Netuno (ou para Poseidon se estiver numa veia mais helênica)! Mexer nos critérios, Jorge, é preciso, porque mexer, assim como navegar, é preciso! (10) (a)

\section{NOTAS FINALES}

a. El editor hace aquí una alusión al poema de Fernando Pessoa "Navegar é preciso" que retoma a su vez una antigua frase del general romano Pompeu en latín "Navigare necesse; vivere non est necesse" y que popularizó el cantante bahiano Caetano Veloso. 
São Paulo, 20 de abril de 2011

À Presidente do V Congresso Brasileiro de Ciências Sociais e Humanas em Saúde

O Fórum de Editores de Revistas da Área de Ciências Sociais e Humanas em Saúde, reunido em 18/04/2011, durante o V Congresso Brasileiro de Ciências Sociais e Humanas em Saúde, com a participação expressiva de editores das diversas revistas do campo da Saúde Coletiva e autores, vem solicitar, pela importância dos assuntos discutidos, a inclusão na agenda da ABRASCO do debate das questões que seguem e o encaminhamento deste documento a Área de Saúde Coletiva da CAPES.

Os participantes concluíram pela urgente necessidade de revisão dos parâmetros de classificação das revistas na área de saúde coletiva da CAPES.

Reiteradamente temos presenciado manifestações de pesquisadores, docentes, autores e editores criticando veementemente a hegemonia de abordagens biomédicas em detrimento da natureza plural, rica e interdisciplinar do campo da Saúde Coletiva, com o risco de exclusão de áreas importantes como as ciências sociais, ambientais, a saúde do trabalhador, gestão, promoção da saúde, etc.

Os participantes verificam esta hegemonia como uma ameaça de empobrecimento do campo e solicitam que sejam respeitadas e valoradas distintamente as características específicas e a diversidade do campo que inclui entre outras as ciências sociais e humanas, e que se considere a produção de critérios qualitativos de avaliação das revistas.

Avaliam que os critérios bibliométricos vêm respondendo mais à lógica de mercado com claro favorecimento dos periódicos internacionais, em detrimento de importantes esforços nacionais, como as citações por meio do SciELO. 
Consideram ainda que a internacionalização não deva se limitar a versão em inglês dos artigos mantendo-se "resíduos" colonialistas, respeitando a circulação de artigos sobre localidades e especificidades geográficas ou sociais singulares.

Percebe-se ainda um distanciamento do caráter formativo de linhas editoriais, que se preocupam em estimular o debate e reflexão entre autores e leitores e, particularmente, na formação de novos autores.

O Fórum recomenda que os editores devam constituir agenda de trabalho visando garantir a multiplicidade de revistas da área, discutir a política de financiamento, promover formas de colaboração entre as novas revistas e revistas consolidadas, e estimular o ingresso de novos participantes na ABEC.

Recomenda ainda a realização de seminários conjuntos entre fórum de editores e fórum de coordenadores de pós-graduação da área.

Presentes ao Forum

Cadernos de Saúde Pública - Suely F. Deslandes

Ciência \& Saúde Coletiva - Maria Cecília de Souza Minayo

Editora Hucitec - Yara Maria de Carvalho Interface, Comunicação, Saúde e Educação - Lilia Blima Schraiber

Physis - Kenneth Rochel de Camargo Jr Revista Brasileira de Ciências Sociais - Mirian da Silveira Pavanelli Revista Brasileira de Saúde Ocupacional - Eduardo Garcia Revista de Saúde Pública - Ivan França Junior Salud Colectiva - Hugo Spinelli Saúde \& Transformação Social - Charles Dalcanale Tesser Saúde e Sociedade - Cleide Lavieri Martins Demais participantes:

Aurea Ianni; Gladys Benito; Helena Ribeiro; Mara de Andréa Gomes; Maria da Penha Costa Vasconcellos; Rodolfo Vilela; e Rubens de Camargo Ferreira Adorno 


\section{REFERENCIAS BIBLIOGRÁFICAS}

1. Criterios de clasificación de las publicaciones científicas argentinas. Salud Colectiva [Internet]. 2010 [citado 4 may 2011];6(3). Disponible en: http://www.scielo.org.ar/scielo.php?script = sci_p df\&pid =S1851-82652010000300009\&Ing = es\&nrm = iso\&tlng $=$ es

2. Coordenação de Aperfeiçoamento de Pessoal de Nível Superior. Qualis Periódicos [Internet]. Brasilia: CAPES; 2010 [citado 6 may 2011]. Disponible en: http://www.capes.gov.br/avaliacao/qualis

3. Critérios de Classificação do Qualis por Área (Triênio 2007 - 2009) [Internet]. CAPES [citado 8 may 2011]. Disponible en: http://qualis.capes.gov. br/webqualis/ConsultaCriterio2008.faces

4. Coordenação de Aperfeiçoamento de Pessoal de Nível Superior, Diretoria de Avaliação. Documento de área 2009: Área de avaliação Saúde Coletiva [Internet]. Capes; 2009 [citado 4 may 2011]. Disponible en: http://qualis.capes.gov.br/ arquivos/avaliacao/webqualis/criterios2007_2009/Criterios_Qualis_2008_22.pdf

5. Camargo Jr KR. O rei está nú, mas segue impávido: os abusos da bibliometria na avaliação da Ciência. Saúde \& Transformação Social [Internet]. 2010 [citado 10 may 2011];1(1). Disponible en: http://www.incubadora.ufsc.br/index.php/saudeetransformacao/article/view/419/469

6. Caramelli B. Classificação dos periódicos no sistema QUALIS da CAPES - a mudança dos critérios é urgente! Revista Brasileira de Ortopedia [Internet]. 2010 [citado 10 may 2011];45(1). Disponible en: http://www.scielo.br/scielo.php? pid $=$ S0102-36162010000100002\&script =sci_arttext

7. Consejo Nacional de Investigaciones Científicas y Técnicas. Manual de Procedimientos del Sistema Integral de Gestión y Evaluación (SIGEVA).
Usuario: Coordinador de Comisión Asesora [Internet]. Buenos Aires: Conicet [citado 20 jul 2010]. Disponible en: http://www.conicet.gov.ar/ webfiles/2009/09/Manual_Coordinador_CA_09. pdf

8. Associação Brasileira de Editores Científicos. Conclusões do Fórum Geral de Áreas: XII ENEC [Internet]. XII Encontro Nacional de Editores Científicos, Águas de Lindóia, São Paulo, Brasil, 23 a 27 de noviembre de 2009 [citado 20 jul 2010]. Disponible en: http://www.abecbrasil.org.br/includes/relatorios-balancetes/Conclusao forum _areas.pdf

9. Rocha-e-Silva M. O novo Qualis, ou a tragédia anunciada. Clinic [Internet]. 2009 [citado 10 may 2011];64(1). Disponible en: http://www.scielo.br/ scielo.php?script = sci_arttext\&pid = S180759322009000100001

10. O Novo Qualis, que não tem nada a ver com a ciência do Brasil. Carta aberta ao presidente da CAPES. Clinics [Internet]. 2009 [citado 12 may 2011];64(8). Disponible en: http://www.scielo.br/ scielo.php?pid = S1807-59322009000800002 $\&$ script $=$ sci_arttext

11. Cabral Filho JE. The CAPES Qualis and beyond. Revista Brasileira de Saúde Materno Infantil [Internet]. 2010 [citado 10 may 2011];10(4). Disponible en: http://homolog.scielo.br/scielo.php? script $=$ sci arttext\&pid = S1519$38292010000400001 \& \operatorname{lng}=$ pt\&nrm $=$ iso\&tlng $=$ en

12. Sociedade Brasileira de Zoologia. Manifesto ao novo Qualis Capes [Internet]. 2009 [citado 12 may 2011]. Disponible en: http://www.sbzoologia.org.br/ noticia interna.php?idnoticia $=24$

13. Ranking coloca revistas científicas brasileiras em "risco de extinção". Jornal da Ciência [Internet]. 6 jul 2009 [citado 12 may 2011]. Disponible en: http://www.jornaldaciencia.org.br/ Detalhe.jsp?id $=64509$

\section{FORMA DE CITAR}

El "impacto" de las políticas nacionales de ciencia y técnica sobre las publicaciones científicas. Salud Colectiva. $2011 ; 7(2): 259-263$. 